\title{
FABRICATION OF COCONUT RAW LEAF EPOXY COMPOSITEFOR SUSTAINABLE HUT ROOFS
}

\author{
K. R. VIJAYA KUMAR", M. THAYUMANAVAN, J. JAYASEELAN \& S. NALLUSAMY \\ ${ }^{1,4}$ Professor, Department of Mechanical Engineering, Dr. MGR Educational and Research Institute, \\ Maduravoyal, Chennai, Tamil Nadu, India \\ ${ }^{2}$ Research Scholar, Department of Mechanical Engineering, Dr. MGR Educational and Research Institute,
} Maduravoyal, Chennai, Tamil Nadu, India

${ }^{3}$ Associate Professor, Department of Mechanical Engineering, Dr. MGR Educational and Research Institute,

Maduravoyal, Chennai, Tamil Nadu, India

\begin{abstract}
The mechanical properties, tensile and flexural strengths of coconut leaf and leaf-fiber reinforced epoxy composite were calculated to assess the possibility of using it as a new material in engineering applications such as making hut roofs for longer life. Addition of epoxy to the leaf fiber ensures fire resistance. This proves vital in prevention of wild-fire in localities with large number of huts made up of such coconut leaves. Also, the making of such cost effective and efficient material in a short span proves helpful during disaster rehabilitation for constructing temporary housing for the victims using the same material for making roofs and walls. Samples are manufactured by the hand lay-up process (70:30) fiber and matrix ratio by weight) and the mechanical properties like tensile, flexural and compressive evaluated using the Universal Testing Machine. Mechanical properties like tensile and flexural strengths for the coconut leaf-fiber-reinforced composite laminates are calculated to be $37 \mathrm{MPa}$ and $71 \mathrm{MPa}$ for dry leaf respectively. It is an eco-friendly, long life and costeffective solution for various housing problems.

KEYWORDS: Coconut leaf, Epoxy, Fire resistance, Tensile strength \& Flexural strength
\end{abstract}

Received: Mar 19, 2020; Accepted: Apr 09 2020; Published: May 02, 2020; Paper Id.: IJMPERDJUN202025

\section{INTRODUCTION}

A Composite material can be well-defined as a mixture of two or more materials that results in improved properties than those of the individual components used alone. In distinction to metallic alloys, each material holds its separate chemical, physical, and mechanical properties. The two components are fiber and matrix. The foremost benefits of composite materials are their high strength to weight and stiffness to weight ratio, when compared with bulk materials, allowing for a weight reduction in the finished parts. The reinforcing phase offers strength and stiffness. In most cases, the reinforcement is tougher, sturdier, and stiffer than the matrix. A fiber has a length that is much larger than its diameter. Continuous-fiber composites generally have a preferred orientation, while discontinuous fibers usually have a random orientation. The matrix phase offers binding property to the reinforcement.

\section{Natural Fiber Reinforced Composite}

The interest on natural fiber-reinforced polymer matrix composite materials is rapidly increasing both in terms of their applications and fundamental research. Natural fiber reinforced composites are renewable, cheap, completely or partially recyclable, and partially biodegradable. Plants, such as cotton, jute, pineapple, bamboo, banana, etc., as 
well as wood are used as a good source of lingo cellulosic fibers, are more and more often used as the reinforcement for composites. Their accessibility, renewability, low density, and price as well as acceptable mechanical properties make them an attractive ecological substitute to glass, carbon and man-made fibers used in the manufacturing of composites. The natural fiber composites are more eco-friendly, and find widespread use in transportation (automobiles, railway coaches, aerospace), military applications, building and construction industries (ceiling paneling, partition boards), packaging, consumer products, etc. Natural fiber-composites have significant potential to substitute conventional materials like metal, plastics and wood in structural and non-structural applications. (Sapuan 2005).

These composite materials impart strength and stiffness to the product, besides having advantages such as low cost, eco friendliness, copious availability and renewable nature. Coconut leaf, the covering of the coconut inflorescence, is an under-exploited material with great potential in this respect. Though considerable research has been carried out on other tissue-types of the coconut palm (Cocos nucifera), e.g., leaf bud sheath (Sapuan et al., 2001), coir (Lai et al., 2005), shell (Sapuan et al., 2003), reports on the use of coconut leaf as a source of fiber in composite materials are very scarce. Moreover, manufacture of fiber- reinforced composite materials strengthens the bonding between fiber and matrix, so that it could resist the applied load. Hence, in the present work coconut leaf-fiber reinforced epoxy composites were fabricated and tested to determine the mechanical characteristics like tensile and flexural strengths.

\subsection{Fabrication}

The composite was made by collecting two green branches of coconut leaves and weaving them in the form of a mat of dimensions (600 X 360 X13 mm). The epoxy resin was made with a composition of Araldite to HY951 hardener in the ratio of (5:1) and mixed well. The approximate quantity of Araldite was $1400 \mathrm{ml}$ and HY951 hardener 262.5ml. The mixture was stirred well to obtain uniform consistence.

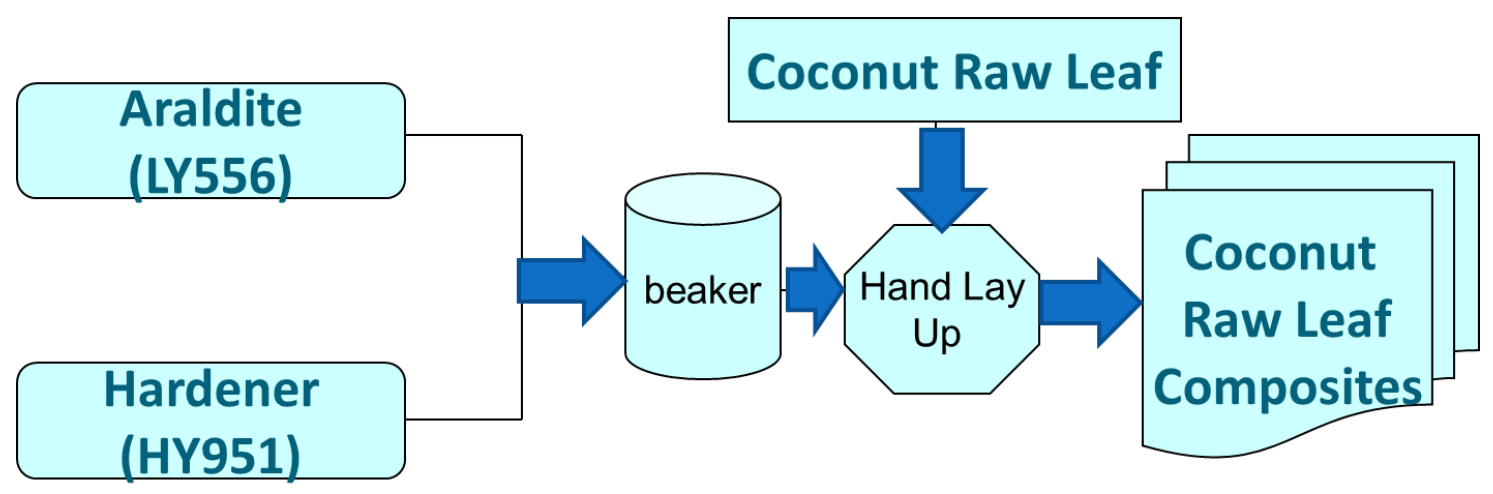

Figure 2: (a): Fabrication Process

A flat gloss paper was laid on the ground. An approximate quantity of $555 \mathrm{ml}$ of the mixed resin (1/3rd Quantity) was poured on the gloss paper, then one of the woven mats was placed and hand pressure was given. This was allowed to dry for about 10 minutes before the second layer of epoxy (555ml) was poured on top of it. Then the second mat was placed on top of the resin at an orientation of 1800 with respect to the first mat. Then the remaining epoxy resin was poured on top of the second mat to give a closure. Then the entire 2-fiber, 3-resin sandwich was covered with a gloss paper. Hand pressure was given until the excess epoxy flowed out and a proper setting was obtained, then the laminate was pressed using hand press and was left undisturbed for one day. After checking the proper curing of the composite, the hand 
press was removed, the gloss paper was torn and the composite made ready.

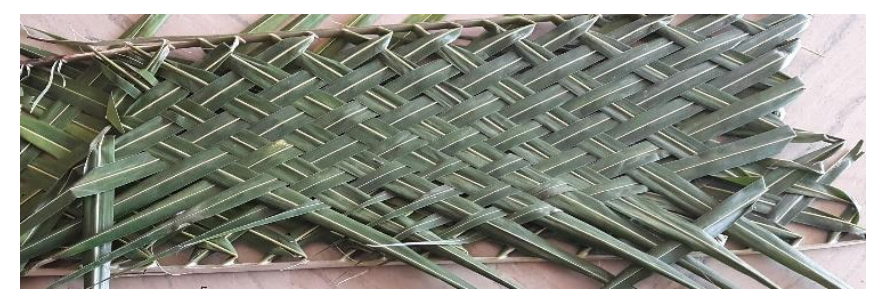

Figure 2: (b). Woven mat of Green Leaf

A second composite was made using dry leaves of coconut which were given a cross-grid arrangement to make a mat of dimensions (400 X 240 X 5 mm). The epoxy resin was made with a composition of Araldite to HY951 hardener in the ratio of (6:1) and mixed well. The approximate quantity of Araldite was $1050 \mathrm{ml}$ and HY951 hardener $175 \mathrm{ml}$. The mixture was stirred well till the desired thickness was obtained. A flat gloss paper was laid on the ground. An approximate quantity $612.5 \mathrm{ml}$ of the mixed resin (1/2 Quantity) was poured on the gloss paper, then the woven mat was placed and hand pressure was given. This was allowed to dry for about 10 minutes before the second layer of epoxy (612.5ml) was poured on top of it. The single fibre, two resin layers was covered with a glossy paper. Hand pressure was given until the excess epoxy flowed out and a proper setting was obtained, then the sandwich was pressed using hand press and was left undisturbed for one day. After checking for proper curing of the composite, the hand press was removed, the gloss paper was torn and the composite made ready.

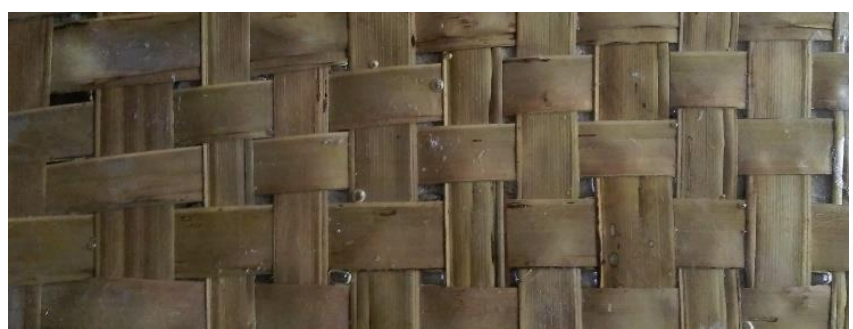

Figure 2: (c) Woven Mats of Dry Leaf

After both the composites were fabricated, they were cut into standard dimensions and the weight was measured. The composition of the materials for both samples is specified in Table 1, as shown below.

\begin{tabular}{|c|c|c|}
\hline $\begin{array}{c}\text { Specimen as per the Sample } \\
\text { Taken (Dimensions) }\end{array}$ & $\begin{array}{c}\text { Epoxy Resin } \\
\text { (wt. in gms) }\end{array}$ & $\begin{array}{c}\text { Fibr ( wt. } \\
\text { in gms) }\end{array}$ \\
\hline Composite 1 (Green Leaf) & 614 & 26 \\
\hline Composite 2 (Dry Leaf) & 427 & 185 \\
\hline
\end{tabular}

\section{TESTING}

\subsection{Tensile Test}

Tensile testing is a fundamental mechanical property test in which a specimen is subjected to a controlled tension until failure. Composite specimens are tested for tensile strength as per ASTM D 3039 test standard. Figs. 3(a) show the tensile test results of both specimens. The tensile strength and elastic modulus are given in Table 2. This result is in agreement with the work done by S.M. Sapuan. The specimen was loaded in servo assisted hydraulic-Universal testing machine having gauge length of $120 \mathrm{~mm}$. The grips were stiffened uniformly and firmly to prevent any slippage. The testing speed 
was set at a rate of $1 \mathrm{~mm} / \mathrm{min}$. As the specimen elongates, the resistance of the specimen increases, and it was detected by a load cell. The vice was fitted firmly and zero reading was observed. Then step by step loading was carried out until the specimen failed at the maximum load $(\mathrm{Fmax}=110 \mathrm{~N})$ for green and $(\mathrm{Fmax}=397 \mathrm{~N})$ for dry leaf composite. As the plotter moves, a load vs deflection curve results on the graph sheet. The stress vs strain curve was obtained from the load Vs deflection curves. The tensile strength and Young's modulus was calculated from the test results.

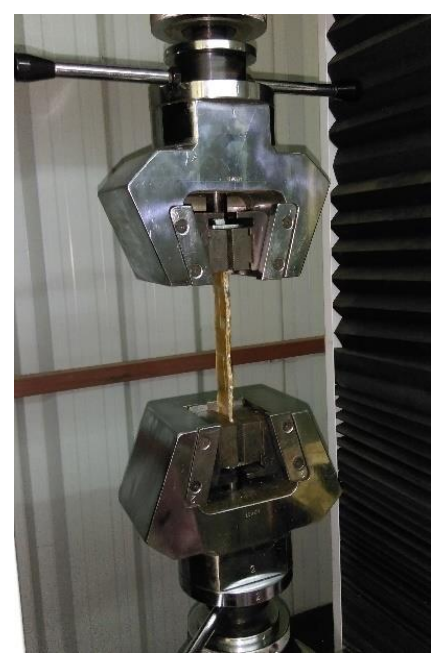

Figure 3: (a) Specimen for Tensile Test in UTM

\subsection{Flexural Test:}

The flexural properties of the composites were evaluated using the Universal Testing Machine, at a cross head speed of $1 \mathrm{~mm} / \mathrm{min}$ and span length of $50 \mathrm{~mm}$. The flexural strength was measured as per the ASTM D 790.

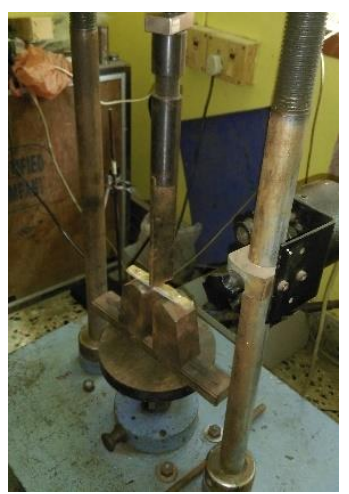

Figure 3: (b) Specimen for Flexural Test in UTM

The test specimen was placed horizontally over the two supports of the testing machine as shown in figure 3(b). The upper grip was moved downward, i.e., the load was applied perpendicular to the specimen surface.

The speed of testing was set at a rate of $1 \mathrm{~mm} / \mathrm{min}$ and the machine was started. The deflection of the specimen was continued until a rupture of the specimen was observed. A plotter plots the load vs deflection curve results on the graph sheet. The stress vs strain curve was plotted from the load Vs deflection curve results. The flexural strength was calculated from the test results. 


\section{RESULTS AND DISCUSSIONS}

\subsection{Tensile Strength}

The experimental values of tensile stress vs strain for composite specimens were plotted and have been shown in Figures 4(a) and 4(b). From the figure, it is seen that the tensile strength value of the Coconut Leaf - epoxy composite is 8 MPa for green leaf fibre and $37 \mathrm{Mpa}$ for dry leaf fibre epoxy composite. The tensile modulus values of dry leaf composite are found to be 4.5 times to that green leaf composite. It is observed that the Dry leaf-epoxy composite has better tensile strength when compared to Green leaf- epoxy composite. Table 2 indicates the flexural strength of the composite materials.

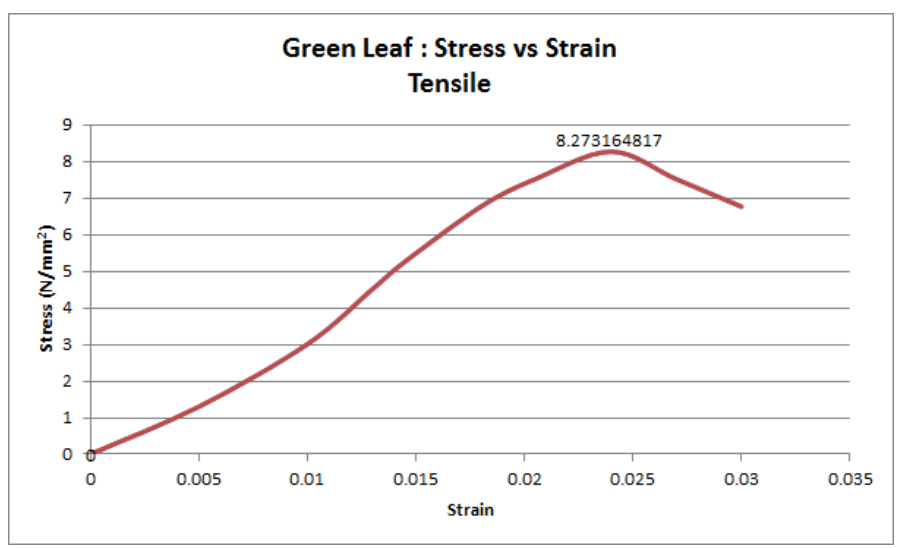

Figure 4(a): Stress Strain Curve of Green Leaf Epoxy Composite

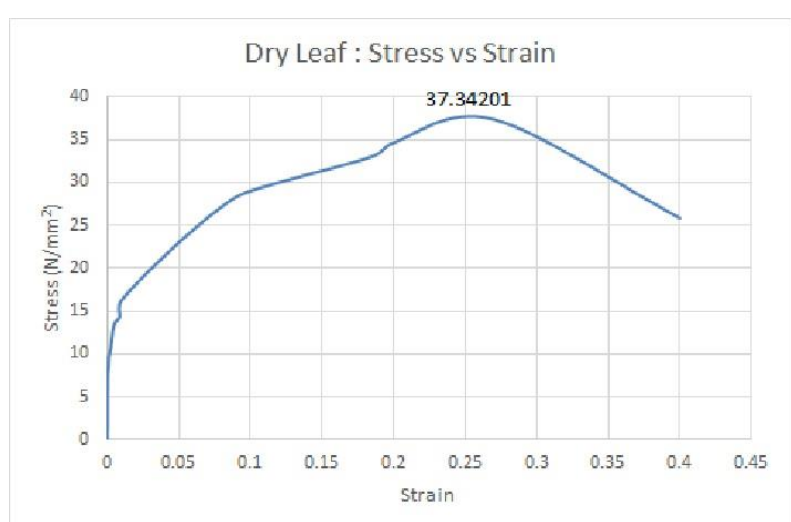

Figure 4(b): Stress vs Strain Curve of Dry Leaf Epoxy Composite

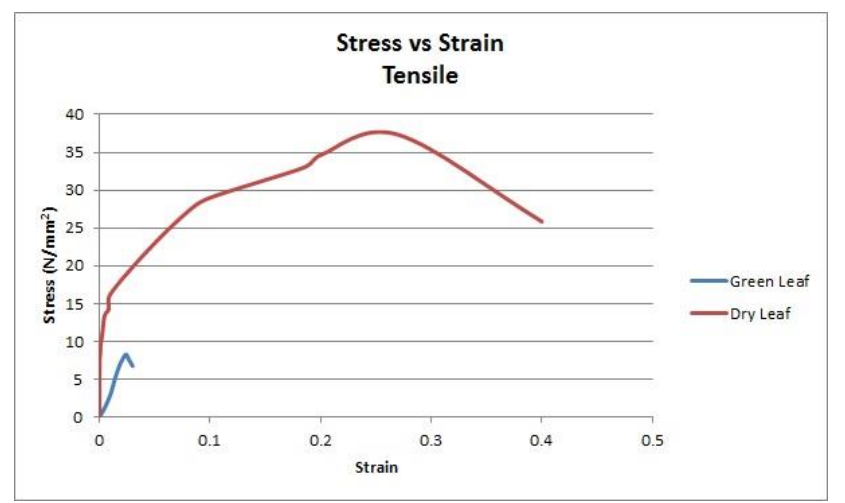

Figure 4(c): Comparison of the Tensile Strength of Composite 
Table 2: Tensile Strength and Young's Modulus of Composite

\begin{tabular}{|c|c|c|}
\hline Specimen & Tensile $\left(\mathrm{N} / \mathrm{mm}^{2}\right)$ & $\begin{array}{c}\text { Young's Modulus } \\
\left(\mathrm{N} / \mathrm{mm}^{2}\right)\end{array}$ \\
\hline Composite 1 (Green Leaf) & 8 & 345 \\
\hline Composite 2 (Dry Leaf) & 37 & 149 \\
\hline
\end{tabular}

\subsection{Flexural Strength}

The experimentally determined values of the flexural stress of the composite specimens are plotted against the flexural strain and are shown in Figures 4(d) and 4(e). A comparative plot of the interlaminar flexural strength of these two specimens is plotted and shown in Figure 4(f). Table 3 indicates the flexural strength of the composite materials. The flexural moduli of Dry Leaf Epoxy composite found to be 1.17 times of Green Leaf Composite.

Table 2: Tensile Strength and Young's Modulus of Composite

\begin{tabular}{|l|c|}
\hline \multicolumn{1}{|c|}{ Specimen } & Flexural Strength $\left(\mathbf{N} / \mathbf{m m}^{\mathbf{2}}\right)$ \\
\hline Composite 1 (Green Leaf) & 60 \\
\hline Composite 2 (Dry Leaf) & 71 \\
\hline
\end{tabular}

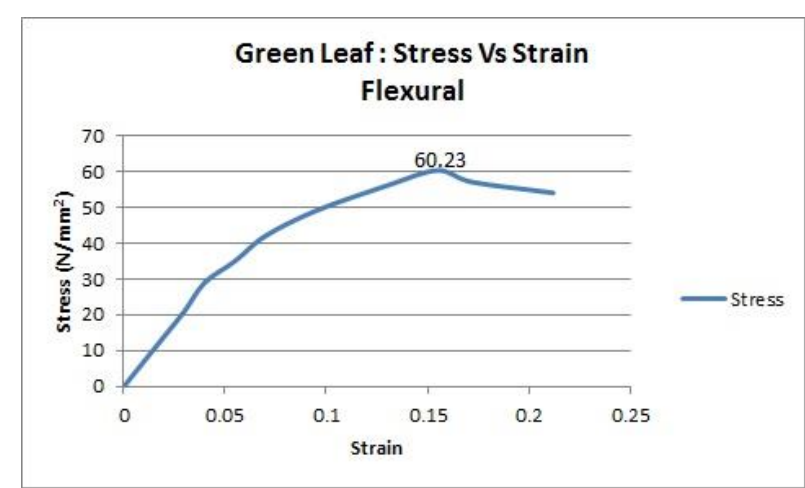

Figure 4(d): Flexural Stress Strain Curve of Green Leaf Epoxy composite

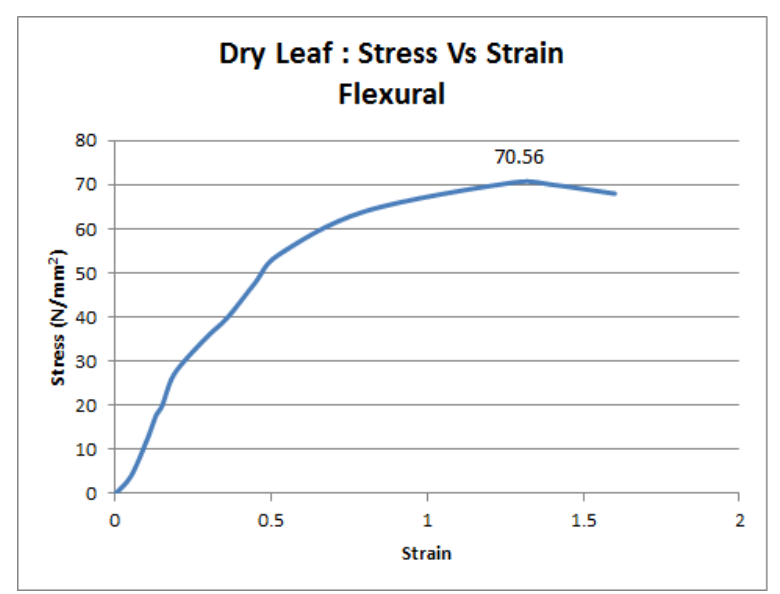

Figure 4(e): Flexural Stress Strain Curve of Dry Leaf Epoxy composite 


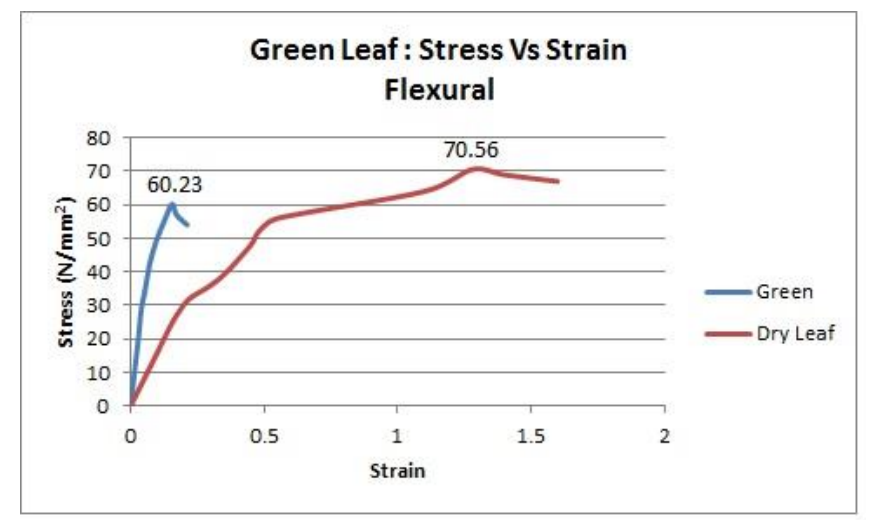

Figure 4(g): Comparison of the Flexural Strength of the Composite

The enhanced flexural properties are due to the formation of a thick bonding network structure between the dry leaf and the epoxy matrix.

\section{APPLICATIONS}

This composite fabrication was aimed at producing durable hut roofs using coconut raw leaf, both dry and green, with epoxy resin. The above results prove that this has a good attempt in making the desired composite.

Further, the applications over this material can be extended in large scale rehabilitation during calamities and also providing improvized housing for the needful. Also, this material is a fire retardant as almost $70 \%$ of the composite is epoxy. Besides this, it is also a good water-proofing solution for roof leakage and seepage. This idea can be effectively used in setting up of resorts.

Future works involve the usage of this composite in combination with other materials such hair composites and Phase Changing Materials (PCM) for various applications.

\section{CONCLUSIONS}

The tensile strength values of dry leaf composite are found to be 4.5 times to that green leaf composite. It is observed that the Dry leaf -epoxy composite has better tensile strength when compared to Green leaf- epoxy composite. It has good specific strength of $16286 \mathrm{~N} . \mathrm{m} / \mathrm{Kg}$ for green leaf composite and $27451 \mathrm{~N} . \mathrm{m} / \mathrm{Kg}$ for dry leaf composite.

The flexural strength of Dry Leaf Epoxy composite found to be 1.17 times of Green Leaf Composite. Hence, we can conclude that the dry leaf epoxy composite shows better mechanical properties when compared to the Green Leaf Epoxy composite. However, these results may vary depending upon the type of fabrication, fiibre: matrix ratio and the number of layers of the individual constituents. It has a good scope for development and wide spread usage and also a good combining ability. It is an eco-friendly, long life and cost-effective solution for various housing problems.

\section{REFERENCES}

1. Ahmed M. El-Assal, U.A. Khashaba,(2007) Fatigue analysis of unidirectional GFRP composites under combined bending and torsional loads, Composite Structures 79, 599-605(2007).

2. American Society for Testing and Materials (ASTM),.ASTM D 638-99-2000 and 790-99-2000. ASTMCommittee on Standards. West Conshocken, PA, pp. 1-13 and 145-151(2000).

3. Autar K.Kaw, Mechanics of composite materials, (1977)CRC press, New York. 
4. Amitava Sil, "Study on Bamboo Composites as Components of Housing System for Disaster Prone Areas", International Journal of Civil Engineering (IJCE), Vol. 5, Issue 3, pp. 11-18

5. Chandramohan.D and Marimuthu K, (2011).IJ “A Review on Natural Fibers" RRAS Vol 8 (2) 194-206.

6. Chirag Garg \& Aakash Jain, “Green Concrete: Efficient \& Eco-Friendly Construction Materials”, IMPACT: International Journal of Research in Engineering \& Technology (IMPACT: IJRET), Vol. 2, Issue 2, pp. 259-264

7. Jayaseelan, J. Palanisamy, P.and K.R. Vijayakumar. (2013). Design fabrication and characterisation of nano-tubes reinforces epoxy carbon fibers, Int. J. Applied Research, 3(2), 228-231

8. Lai, C.Y., Sapuan, S.M., Ahmad, M., Yahya, N. and Dahlan, K.Z.H.M. (2005). Mechanical and electrical properties of coconut coir fibre reinforced polypropylene composites. Polymer-Plastics Tech. Eng., 44 (4): 1-14(2005)

9. Mao, H. Mahadevan, S. Fatigue damage modelling of composite materials, Vanderbilt University, P.O. Box 1831B, Nashville, TN 37235, USA

10. M. M. B. H. Salleh, Z. Salleh, M. S. Rosdi \& S. M Sapuan, "Mechanical Properties of Coconut Carbon Fibre/Epoxy Composite Material”, International Journal of Mechanical Engineering (IJME), Vol. 2, Issue 3, pp. 55-62

11. Nagendra V. Akshantala, Ramesh Talreja, (1998)A mechanistic model for fatigue damage evolution in composite laminates, Mechanics of Material 29, 123-140.

12. Reis, P. N. B. ,Ferreira,J. A. M.,, F.V. Antunes, F . Costa, V. J.D. M. (2007)Flexural behaviour of hybrid laminated composites, Composites: Part A 38 1612-1620.

13. Sapuan, S.M., Hassan, M.Y. and Kassim, M.R. Tensileand (2001).flexural properties of epoxy composites based oncoconut fibre. Cien. Tecnol. dos Mater, 13 (1), $41-43$.

14. Robert M. Brooks, "Role of Smoke Alarms in Fire Disaster Prevention Management for Homes", International Journal of Humanities and Social Sciences (IJHSS), Vol. 7, Issue 3, pp. 1-4

15. Zuo Sun, Isaac M. Daniel, J.J. Luo,(2003) Modeling of fatigue damage in a polymer matrix composite, Materials Science and Engineering A361302-311.

\section{AUTHOR'S PROFILE}

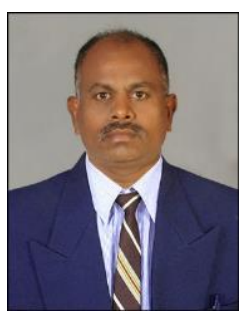

Dr. K. R. Vijaya Kumar, working as Professor in Department of Mechanical Engineering at Dr. MGR Educational and Research Institute, Tamil Nadu, India. He did his Ph.D in Composite Materials at Anna University in the year 2011. He did his M.E (Engineering Design) at Anna University in the year 2001 and B.E (Mechanical Engineering) at Bharathi University in the year 1993. He has published more than 30 articles in various reputed journals. He has guided 4 Ph.D 's. He successfully completed three defense funded projects as co-investigator. His areas of specialization is composites materials, nano technology and engineering design. E-mail ID: vijayakumar.mech@drmgrdu.ac.in 


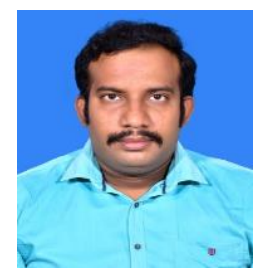

M.Thayumanavan, obtained his Diploma in mechanical engineering in the year 2011 from Vel Tech Polytechnic College, Chennai. He did his B.E degree in Mechanical Engineering in the year 2014 from Jeppiaar Engineering College, Chennai. He did M.E degree in manufacturing engineering in the year 2017 from St. Joseph's College Of Engineering, Chennai. He has worked as assistant professor from the academic year of July-2017 to April 2018 in the department of mechanical engineering in Chendhuran College Of Engineering And Technology, Pudukkottai. Currenltly, he is pursuing his Ph.D in Dr. M.G.R educational and research institute, Chennai. He has published 2 research papers in international journal. E-mail ID:thayu11psp@gmail.com

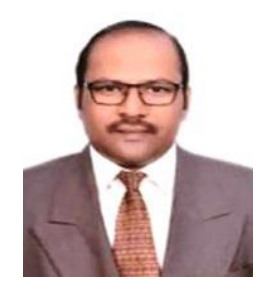

Dr. J.Jayaseelan is working as Associate professor in the Department of Mechanical Engineering, Dr. MGR Educational and Research Institute, Chennai, India. His area of interest was composite materials. He completed his PhD in Bio degradable fibre composite during February 2018. He completed his post-graduation in manufacturing in the year 2009 and his graduation in mechanical engineering in the year 1997. He has got 23 years of rich experience in industry, research and teaching. He has published four journal papers in reputed journals. He is jointly holding a patent for innovation in collapsing mechanism. He successfully completed three defense funded projects as co-investigator. He has developed many natural fibre composite materials and still working on development of few application specific materials. E-mail ID: see_lan@yahoo.com

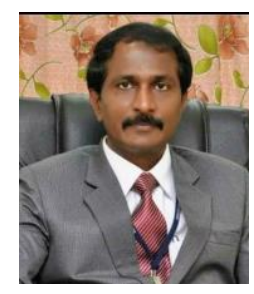

Dr S Nallusamy is currently working as Professor and Dean in the Department of Mechanical Engineering at Dr. M G R Educational and Research Institute, Chennai, Tamil Nadu, India. He did his PhD in Study of Vehicle Maintenance System in Passenger Transport of Public Sector Undertaking Tamil Naduat Jadavpur Universityin the year 2009. He did his M.E(Industrial Engineering) at Anna University in the year 2004 and B.E(Mechanical Engineering) at Madras Universityin the year 1990. He is having about 27 years of Teaching and Research Experience with more than 170 Research articles in reputed national and international journals. He also has published five Text books with ISBN number. He has been guided for $9 \mathrm{PhD}$ scholars and about 45 PG Scholars. His area of specializations are Composite materials, Nano Technology, Lean Manufacturing and SCM.E-mail I:ksnallu@gmail.com 

